\title{
The MDGs and Beyond: Can Low Carbon Development be Pro-poor?
}

\author{
Frauke Urban
}

\begin{abstract}
Climate change adaptation and mitigation needs to cut across all poverty reduction efforts, including any post-2015 architecture. However, low carbon development (LCD) debates to date have been mainly about high- and middle-income countries. There are good reasons why even the poorest countries with low emissions might be interested in pursuing LCD. This article argues that we need to link up pro-poor policy debates with the low carbon debates as part of a post-MDG agenda. The article explores several policy responses to $L C D$ and analyses how pro-poor these policy responses are.
\end{abstract}

\section{Introduction}

Climate change poses a serious threat to international development efforts. Climate change adaptation and mitigation needs to cut across all poverty reduction efforts, including any post-2015 architecture.

Low carbon development (LCD) debates to date have been mainly about high- and middle-income countries. However, there are good reasons why even the poorest countries with low emissions might be interested in pursuing low carbon development. Indeed, LCD can be an opportunity for low-income countries to pursue pro-poor development in a carbon-constrained world. This article argues that we need to link up pro-poor policy debates with the low carbon debates as part of a post-Millennium Development Goal (MDG) agenda. The article explores several policy responses to LCD and analyses how pro-poor these policy responses are.

\section{The MDGs and climate change}

As livelihoods shift in response to more extreme climatic conditions, issues of climate change adaptation and mitigation need to cut across all poverty reduction efforts, including any post2015 architecture. Despite a goal dedicated to environmental sustainability, some of the fundamental criticisms of the MDGs have been based on issues of sustainability and the lack of attention to tackling climate change - the impact of which is likely to affect poor people more than others.

Climate change is directly related to the poverty concerns of the MDGs (see Table 1).

The observed impacts of climate change include melting glaciers, increases in global surface temperatures, heavier precipitation, increases in tropical cyclone activity and higher frequency of droughts especially in the (sub) tropics (IPCG 2007). This will have severe effects on people living in vulnerable areas, such as people living in drought-prone areas where climate change will deteriorate the already harsh living conditions which can result in famines and malnutrition.

Development pathways which aim at tackling climate change while at the same time aiming at social and economic development and achieving the MDGs, are urgently needed. LCD can be one way to achieve this.

\section{What is low carbon development?}

There is currently no internationally agreed definition of LCD. Definitions that do exist mainly focus on mitigation which neglects the importance LCD can play in low-income countries and adaptation. The recent Department for International Development (DFID) White Paper (2009: 58) defines low carbon development (LCD) as follows: 
Table 1 MDGs 1-7 and climate change relevant poverty impacts

Millennium Development Goals

Goal 1: Eradicate extreme poverty and hunger

Goal 2: Achieve universal primary education

Goal 3: Promote gender equality and empower women

Goal 4: Reduce child mortality

Goal 5: Improve maternal health

Goal 6: Combat HIV/AIDS, malaria and other diseases

Goal 7: Ensure environmental sustainability

\section{Climate change relevant poverty impacts}

Climate change is likely to impact on poor people's livelihoods and food security.

The climate-induced destruction of infrastructure, loss of livelihoods and disaster-related migration could be a barrier to achieving universal primary education and gender equality in education.

Climate change-induced extreme weather events are likely to result in higher prevalence of vector- and water-borne diseases, declining food security and decreased availability of potable water.

Climate change will directly impact on natural resources, ecosystems and the earth's natural cycles. This is predicted to reduce the quality and quantity of natural resources and ecosystems.
Low carbon development means using less carbon for growth:

1 Using less energy, improving the efficiency with which energy is used and moving to low or zero carbon energy sources

2 Protecting and promoting natural resources that store carbon (such as forests and land)

3 Designing, disseminating and deploying low or zero-carbon technologies and business models

4 Policies and incentives which discourage carbon intensive practices and behaviours.

The definition is green growth-centred (see below). LGD has been defined more broadly by Skea and Nishioka (2008: 6) as:

... actions that are compatible with the principles of sustainable development, ensuring that the development needs of all groups within society are met, make an equitable contribution towards the global effort to stabilize the atmospheric concentration of $\mathrm{CO}_{2}$ and other greenhouse gases at a level that will avoid dangerous climate change, through deep cuts in global emissions, demonstrate a high level of energy efficiency and use low-carbon energy sources and production technologies, adopt patterns of consumption and behaviour that are consistent with low levels of greenhouse gas emissions.
However, definitions such as by Skea and Nishioka focus on mitigation which neglects the importance adaptation can play in low-income countries. This definition is also focused on developed countries, as it calls for 'deep cuts in [global] emissions'.

At a global level this is crucial, but at a national level this is not an option for low-income countries, as they have very low emissions and the main issue is how to achieve development in times of climate change.

LCD can be thought of in terms of changes in production such as changes in supply or economic growth and/or consumption such as demand, consumption patterns or lifestyles. Figure 1 and Table 2 give four contrasting interpretations, resulting from where policymakers place themselves on two different dimensions of response: their approach to growth; and their focus on production or consumption-related policy measures.

The first two types of LCD (here labelled 'Green Economy' and 'Green Lifestyles') assume that economic growth is compatible with significant reductions in carbon emissions - the latter two (here labelled 'Equilibrium Economy' and 'Coexistence with Nature') assume it is not. The Green Economy and Equilibrium Economy approaches both put the emphasis on reducing the production of carbon through technological 


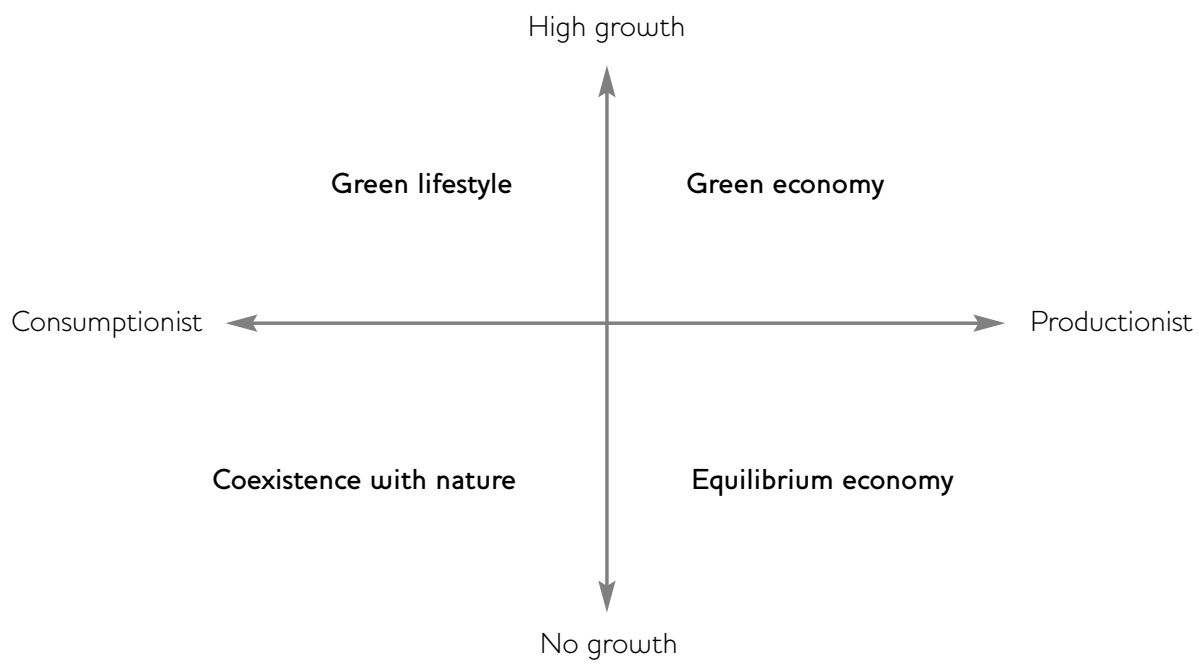

changes (from inefficient to more efficient, from polluting to less polluting) and/or sectoral changes (structural changes taking place in the economy). For example in China, many inefficient older coal-fired power plants are being replaced with more efficient, less polluting new plants and in India, the service economy has been rapidly growing over recent years, while the share of agricultural value added has declined (Van Ruijven et al. 2008).

The Green Lifestyles and Coexistence with Nature approaches focus on reducing demand through lifestyle and behavioural changes as well as through sectoral and technological changes. Behavioural change refers to changes in behaviour and lifestyle: using public transport instead of travelling by car, switching to 'green' electricity instead of fossil fuel-powered electricity, buying local products instead of imported 'air mile products'. Not all options are equally valid for developing countries and specific groups as discussed below.

Of course, the options presented in Table 1 are not mutually exclusive. For example, most country policymakers will favour a mix of production and consumption side approaches to LCD. The debate about the appropriate mix is part of the wider discussion.

While general discussions about the limits of decoupling growth from emissions are fraught (see Barrett et al. 2008; Ockwell 2008 for details), many case studies argue that low carbon growth is possible, e.g. for China (IEA 2007), India (World Bank 2008), South Africa (Government of South Africa 2008) and Mexico (Project Catalyst 2008).

\section{How can low carbon development be pro-poor?}

Low-income countries have contributed least to climate change. For them, LCD is not about cutting emissions, but about the benefits and opportunities LCD can bring for achieving a higher development status. There are good reasons why LCD can be beneficial for lowincome countries.

Low carbon development can be beneficial to the poor, as it can provide climate-friendly modern energy for electrification as an alternative to traditional fuels and fossil fuels, increased energy security, sustainable use of forest and land use resources, improved environmental quality, increased community participation, provision of 'green jobs' and contributions to capacity building.

There are also cost reasons. Fossil fuel resources such as oil are costly and can lead to a 'carbon lock-in' with infrastructure and investments bound to a carbon-intensive economy for decades. Thus, relying on them can mean greater costs in the long run. Also, the emission trading scheme under the United Nations Climate Change Convention (UNFCCC) has 
Green Economy Focuses on the production-side of an economy and on how goods and services can be produced with lower emissions. It aims at decoupling economic growth from carbon emissions (e.g. halving emissions, but doubling GDP)

Green Lifestyles Focuses on the consumption-side of a growing economy and on the consumer's ability to reduce emissions by consuming climate-friendly products. It implies lifestyle changes and behavioural changes and also leads to a decoupling of carbon emissions (e.g. halving emissions, but doubling GDP)

Equilibrium Economy Focuses on the production-side of an economy and aims at social development rather than growth. No decoupling is necessary as growth is neutral (e.g. halving emissions, but keeping GDP stable)

Coexistence with Nature Focuses on the consumption-side of an economy and aims at social development rather than growth. No decoupling is necessary as growth is neutral (e.g. halving emissions, but keeping GDP stable)
Focus mainly on mitigation, although adaptation also plays a role. Approach: Technological change, sectoral change

Focus equally on mitigation and adaptation.

Approach: Behavioural changes, sectoral change, technological change

Focus mainly on mitigation, although adaptation also plays a role. Approach: Technological change, sectoral change

Focus equally on mitigation and adaptation.

Approach: Behavioural change, sectoral change, technological change introduced a price for carbon. Having a high price attached to carbon could mean a competitive disadvantage for low-income countries in relation to global markets.

The types of appropriate policy measures will differ for different country income groups, resource availability and the LCD definition taken. LCD pathways can differ between countries having high fossil fuel resources and those not having abundant fossil resources. Countries with high fossil fuel resources usually tend to promote primarily so-called 'cleaner' fossil energy, which emits less greenhouse gas emissions than conventional coal and oil (such as natural gas or fossil fuel power plants with carbon capture and storage). Countries with low fossil fuel resources usually tend to promote primarily renewable energy. Forest resource availability can also be important: countries with large forest resources tend to aim to achieve LCD through climate-friendly forest and land use management. There are several UNFCGC mechanisms for LCD as indicated in Table 3.

Currently, only the Clean Development Mechanism (CDM) is accessible for developing countries. The first commitment period of the Kyoto Protocol will end in 2012 and a new climate change agreement will be needed for the post-2012 era. Mechanisms for LCD will be one of the key issues for a new climate agreement. The CDM might be reformed into a mechanism which can be used at programme and sectoral level, while it has only been used at project level so far. Two other mechanisms are currently in discussion and might be part of a future climate change agreement: Reducing Emissions from Deforestation and Forest Degradation (REDD) and Land Use, Land Use Change and Forestry (LULUCF). Reducing Emissions from Deforestation and Forest Degradation is currently considered to be important with respect to developing countries. Brazil, Indonesia and the Democratic Republic of Congo have extensive forest resources which are threatened by deforestation and degradation.

Other proposed UNFCGC mechanisms are Nationally Appropriate Mitigation Actions (NAMAs) for developing countries. The purpose of NAMAs is to create national mitigation options which are in line with domestic policies and which are developed in 'the context of sustainable development, supported and enabled by technology, financing and capacity building, in a measurable, reportable and verifiable manner' (IEA/OECD 2009: 7). Each NAMA will depend on the nationally appropriate mitigation actions and the financial support available.

Besides the UNFCCG mechanisms, there are many other options of how to achieve LCD 

in developing countries. Developing countries gain access to climatefriendly technology; developed countries gain emission reduction credits to offset their emissions.

Emission Trading (EM)
Mechanism that sets a cap on greenhouse gas emissions and introduces a trading system. Once emission allowances are exceeded, emission credits must be bought from those who have emitted less. Emission Trading is currently in place for developed countries only, but might be extended to a global level in the future.

Joint Implementation (J)

Developed countries can invest in emission reduction projects in other developed countries as an alternative to reducing emissions domestically. $\mathrm{Jl}$ is currently in place for developed countries only.

Reducing Emissions from Deforestation and Forest Degradation (REDD) and Currently under discussion in relation to a future climate change agreement. Developing countries could be paid for climate-friendly Land Use, Land Use Change and Forestry (LULUCF)

forest and land use management; developed countries could gain emission reduction credits to offset their emission obligations.

Nationally Appropriate Mitigation Actions (NAMAs)

\begin{abstract}
The purpose of NAMAs is to outline national mitigation options which are in line with domestic policies and which are developed in 'the context of sustainable development, supported and enabled by technology, financing and capacity building, in a measurable, reportable and verifiable manner' (IEA/OECD 2009).
\end{abstract}

depending on each country's national and local priorities and plans, and the funding and technologies that are available. It is important to have policies and practices in place which are suited for the national circumstances and the local needs. The meaning, scope and scale for LCD differ within different groups of countries. Upperand middle-income groups in developing countries, particularly in middle-income countries, may have consumption patterns which are in some ways similar to developed countries. Reducing excessive consumption and making 'greener' choices can therefore be an important issue. The poor in developing countries have however contributed very little to climate change and the main priority is social and economic development. For poor and vulnerable groups and low-income countries, the main issue is how to achieve development in times of climate change. The benefits and opportunities of LCD such as provision of 'green' jobs, increased access to modern technology and access to electricity, contribute to energy security and improved environmental quality.

Other initiatives on low carbon development outside of the UNFCCG include the United Nations Environment Programme's (UNEP 2009) Global
Green New Deal. UNEP proposes a Green Economy Initiative in which 1 per cent of global GDP over the period 2009-10 should be used as a fiscal stimulus package to build a sustainable 'green' future which can revive the world economy while reducing carbon dependency and ecosystem degradation. UNEP suggests targeted stimulus spending, changes in domestic policies and changes in international policy architecture. The proposed fiscal stimulus should promote energy-efficient buildings, sustainable transport and renewable energy. UNEP also mentions that under the UNFCGC global carbon markets need to be developed and the Clean Development Mechanism should be redesigned.

What is missing so far in the debate is an explicit pro-poor concern or concern for distributional issues, i.e. how do different types of LCD impact on the poor? Since the main goal of the UNFCGC mechanisms is to reduce greenhouse gas emissions we need to link up pro-poor policy debates with the low carbon debates as part of a post-MDG agenda or paradigm.

LCD can be beneficial to the poor, as it can open up new opportunities. LCD can create new 'green' jobs and new 'green' industries. The need 
for green jobs for the poor has been stressed by a recent United Nations Development Programme (UNDP 2009) report.

Green jobs are defined by UNDP (2009: 2) as:

... involving the implementation of measures that reduce carbon emissions or help realise alternative sources of energy use ... [to] align poverty reduction and employment creation in developing countries with a broader set of investments in environmental conservation and rehabilitation to also preserve bio diversity, restore degraded land, combat erosion, and remove invasive aliens etc ... well designed interventions can contribute directly to the poverty-environment nexus by allowing income generated from environmental activities to ease the pressure on generating income through exploiting the environment. Environmental sector targeted public employment programmes can also be deployed to specifically address environmental concerns and create employment for the poor at the same time.

In addition to green jobs for the poor, LCD can provide climate-friendly energy for electrification and can increase the energy-generating capacity which is often scarce in developing countries. This can be achieved, e.g. by renewable energy, which already plays a prominent role at the community level in many poor communities in developing countries. LCD can result in the introduction of energy-efficient technologies which use fewer resources and reduce costs. LCD can lead to an enhanced energy security due to relying on fewer fossil fuel imports and instead, using more locally abundant energy sources such as solar and hydropower. Forests can serve as carbon sink services and there could be possibilities for receiving funding for sustainable management of these forests and other land use areas, which might be profitable for local farmers and foresters. There can be increased community participation and capacity building due to community-based renewable energy and forest management projects.

Furthermore, LCD can lead to improved environmental quality such as improved air quality and safeguarding of natural resources which also has social co-benefits, e.g. on health. Most developing countries rely primarily on traditional biomass such as fuelwood. However, finite fossil fuel resources like coal, oil and natural gas are increasingly being used as countries develop. Fossil resources lead to a 'carbon lock-in' (as noted earlier).

Key policies for pro-poor LCD can be drawn by linking up pro-poor growth debates (see discussion in McKay and Sumner 2008; Sumner and Tiwari 2009) and LCD debates (Barrett et al. 2008; NIES 2006; Ockwell 2008; Urban 2009). The following examples indicate policies for pro-poor LCD:

\section{Redistributive policies and public} expenditure. This can take place, e.g. when the government revenues made by 'green' industries are distributed to pro-poor sectors such as health and education.

- Support for specific sectors which are crucial for the poor such as agriculture and forestry. This requires specific sectoral investments, market development and infrastructure for pro-poor productive sectors.

- Social protection for adaptation and combining the synergies between mitigation and adaptation. Social protection measures to reduce vulnerability to climate change, for example.

- Community participation. LCD provides opportunities to involve communities on a small-scale local level, such as rural electrification with renewable energy. This can enable sharing the profits from LCD at a community level.

- Development to foster capacity for the legislative, economic and technical frameworks needed to achieve low carbon pathways. Capacity building to ensure local policymakers can develop the legislative frameworks needed for LCD, for example.

- Increasing the rate of 'green' job creation. This will require investments, development of the finance sector and increased investments in small-scale infrastructure.

- Pro-poor biofuel policies. Biofuels are considered climate-friendly fuels, but can lead to a competition between land for food and land for biofuels, which can result in an increase in food prices. This usually hits the poorest the hardest. Pro-poor biofuel policies therefore need to be introduced which promote the growing of biofuels by the poor, create local employment opportunities and enable the investments to go to low-income countries (Peskett and Prowse 2008). 
- Pro-poor forest and land use policies. REDD and LULUCF are two possible mechanisms where payments from developed countries are directed to developing countries for climatefriendly forest and land use management and thus could benefit the poor by ensuring that smaller farmers and foresters can engage in the carbon market (Peskett and Prowse 2008).

\section{Conclusions}

The development model of 'pollute first, clean up later' is no longer viable. New development pathways are needed in times of climate change. LCD is a development pathway, which can achieve economic and social development while tackling global climate change.

LCD needs to be pro-poor. LCD should therefore be accompanied by mechanisms, incentives and institutions to support a pro-poor low carbon economy such as improved access to low carbon technology for the poor, and targeting support to those groups that are the most vulnerable to the impacts of climate change.

The Intergovernmental Panel on Climate Change's (IPCC 2007) Fourth Assessment Report warns that global greenhouse gas emissions need

\section{References}

Barrett, M.; Lowe, R.; Oreszczyn, T. and Steadman, P. (2008) 'How to Support Growth with Less Energy', Energy Policy 36.12: 4592-9

DFID (2009) Eliminating World Poverty: Building our Common Future, DFID White Paper, London:

Department for International Development

Government of South Africa (2008) South Africa

Long-Term Mitigation Scenarios, www.environment.gov.za/HotIssues/2008/LTM S/A\%20LTMS\%20Scenarios\%20for\%20SA.pdf (accessed 5 November 2009)

IEA (2007) World Energy Outlook 2007, Paris:

International Energy Agency (IEA)/

Organisation for Economic Co-operation and Development (OECD)

IEA/OECD (2009) Linking Mitigation Actions in Developing Countries with Mitigation Support: A Conceptual Framework, www.oecd.org/dataoecd/ 27/24/42474721.pdf

IISD (2005) Vulnerability and Adaptation in Developing Countries, International Institute for Sustainable Development to be cut by 80 per cent in 2030 compared with 2000 levels, to avoid 'dangerous climate change' (defined as a global temperature rise above 2 degrees Celsius). Leading scientists suggest that even more drastic cuts are needed and warn that a temperature rise above 2 degrees is becoming more and more likely (Richardson et al. 2009). A rise above 2 degrees will lead to abrupt and irreversible changes (IPCC 2007). These changes will make it difficult for contemporary societies to cope with and they are expected to cause severe societal, economic and environmental disruptions which will severely threaten international development throughout the twenty-first century and beyond (Richardson et al. 2009).

Mitigation of greenhouse gases is therefore becoming increasingly important for global development. High-income countries need to make drastic emission cuts now. In the long run emerging economies and middle-income countries with high emissions will also need to reduce their emissions. Low-income countries have very low emissions. LCD for low-income countries will primarily be about achieving development in times of climate change. This means that equitable pro-poor low carbon development pathways are increasingly needed.

IPCG (2007) Fourth Assessment Report on Climate Change, Intergovernmental Panel on Climate Change, www.ipcc.ch/publications and_data/publications_ipcc_fourth assessment_report_synthesis_report.htm (accessed 5 November 2009)

McKay, A. and Sumner, A. (2008) 'Economic Growth, Inequality and Poverty Reduction: Does Pro-Poor Growth Matter', IDS In Focus 3.2, Brighton: IDS

NIES (2006) Developing Visions for a Low Carbon Society (LCS) Through Sustainable Development. Executive Summary, Ibaraki: National Institute for Environmental Studies

Ockwell, D.G. (2008) 'Energy and Economic Growth: Grounding our Understanding in Physical Reality', Energy Policy 36.12: 4600-4

Peskett, M. and Prowse, L. (2008) 'Mitigating Climate Change: What Impact on the Poor?', ODI Opinion 97, April, London: Overseas Development Institute 
Project Catalyst (2008) Low-Carbon Growth: A Potential Path for Mexico, Centro Mario Molina: Project Catalyst

Richardson, K.; Steffen, W.; Schellnhuber, H.J.; Alcamo, J.; Barker, T.; Kammen, D.M.; Leemans, R.; Liverman, D.; Munasinghe, M.; Osman-Elasha, B.; Stern, N. and Wæver, O. (2009) Climate Change. Global Risks, Challenges and Decisions, Synthesis Report, http://climatecongress.ku.dk/pdf/ synthesisreport/ (accessed 4 November 2009)

Skea, J. and Nishioka, S. (2008) 'Policies and Practices for a Low-carbon Society', Climate Policy 8, Supplement Modelling Long-Term Scenarios for Low-Carbon Societies: 5-16 Sumner, A. and Tiwari, M. (2009) After 2015, Basingstoke: Palgrave

UNDP (2009) Green Jobs for the Poor: A Public Employment Approach, Poverty Reduction
Discussion Paper PG/2009/002, United Nations Development Programme, www.undp.org.gy/documents/bk/ PG-2009002-discussion-paper-green-jobs.pdf (accessed 4 November 2009)

UNEP (2009) Global Green New Deal, policy brief, www.unep.org/pdf/A_Global_Green_New_Deal _Policy_Brief.pdf (accessed 4 November 2009)

Urban, F. (2009) Enabling Environments for Low Carbon Economies in Low Income Countries, London: Catholic Fund for Overseas Development

Van Ruijven, B.; Urban, F.; Benders, R.M.J.; Moll, H.C.; Van der Sluijs, J.; De Vries, B. and Van Vuuren, D.P. (2008) 'Modeling Energy and Development: An Evaluation of Models and Concepts', World Development 36.12: 2801-21

World Bank (2008) Low Carbon Growth in India, Washington DC: World Bank 